1 Dalla Lana School of Public Health, University of Toronto, Canada

2 Johns Hopkins University Bloomberg School of Public Health, Baltimore, USA

3 Saw Swee Hock School of Public Health, National University of Singapore, Singapore

4 Department of Global Health and Development, London School of Hygiene and Tropical Medicine, London, UK

5 Institute of Health Policy, Management, and Evaluation, University of Toronto, Canada

6 Independent Panel for Pandemic Preparedness and Response Secretariat

7 School of Public Health, Boston University, USA

8 State Key Laboratory of Respiratory Disease, National Clinical Research Centre for Respiratory Disease, Guangzhou Institute of Respiratory Health, First Affiliated Hospital of Guangzhou Medical University, Guangzhou Medical University, China

9 Department of Thoracic Surgery, Guangzhou Institute for Respiratory Health, The First Affiliated Hospital of Guangzhou Medical University, China

10 Faculty of Medical and Health Sciences, University of Auckland, New Zealand

Correspondence to: S Wu shishi.wu@utoronto.ca

Cite this as: BMJ 2021;375:e067508 http://dx.doi.org/10.1136/bmi-2021-067508 Published: 29 November 2021

COVID-19 PREPAREDNESS AND RESPONSE: IMPLICATIONS FOR FUTURE PANDEMICS

\title{
Aggressive containment, suppression, and mitigation of covid-19: lessons learnt from eight countries
}

Shishi Wu and colleagues examine three distinct response strategies for covid-19 in eight countries and argue that aggressive containment is the optimal approach to limiting loss of lives and livelihoods and achievable in the absence of vaccines and effective therapies

Shishi Wu, ${ }^{1}$ Rachel Neill, ${ }^{2}$ Chuan De Foo, ${ }^{3}$ Alvin Qijia Chua, ${ }^{3}$ Anne-Sophie Jung, ${ }^{4}$ Victoria Haldane, ${ }^{5}$ Salma M Abdalla, ${ }^{6,7}$ Wei-jie Guan, ${ }^{8,9}$ Sudhvir Singh, 6, 10 Anders Nordström, ${ }^{6}$ Helena Legido-Quigley 3,4,

Early modelling studies in the covid-19 pandemic proposed two distinct response

strategies-suppression and mitigation. $\cdot^{1-3}$ As the pandemic evolved, researchers proposed a third strategy, aggressive containment, drawing on successful lessons from countries that had achieved covid-19 elimination in the interim. ${ }^{45}$ We review the application of these three strategies in eight countries in the first year of the pandemic and relate the findings to trade-offs that occurred as a result of implementation. We aim to provide guidance for optimising health and economic outcomes in the absence of vaccines and effective treatments.

\section{Defining response strategies}

Aggressive containment is usually defined as zero community transmission for more than 28 days, with the understanding that outbreaks might arise from border control failure..$^{6}$ This strategy rapidly reduces disease burden by lowering covid-19 cases, deaths, and the risk of overwhelming the health system. After community transmission is eliminated, domestic control measures can be lifted, and daily activities can resume largely without restriction. Suppression, on the other hand, aims to minimise the number of covid-19 cases without expecting to end community transmission. Modelling studies indicate that suppression cannot prevent an epidemic but can delay it until population immunity is reached through immunisation or natural infection. ${ }^{157}$ Mitigation aims to minimise the effects of the pandemic on vulnerable populations and to avoid overwhelming health systems by permitting controlled transmission in low risk groups. ${ }^{8}$

Different response strategies are put into use through combinations of public health interventions, which can be categorised into three groups: case based (such as case detection, contact tracing, and isolation), population based (such as mask wearing and physical distancing), and border control measures (such as travel bans and mandatory quarantine requirements). ${ }^{9}$ Community engagement, whereby individuals and groups are involved in delivering services and supporting the uptake of control measures, was commonly included in the response strategy. We looked at the public health interventions and community engagement activities implemented in eight countries with different response strategies (box 1). We also examined the preceding determinants to developing and sustaining these interventions.

Box 1: How countries were categorised by their response strategies

$\overline{\text { We purposively selected eight countries and categorised }}$ their responses to the initial stages of the pandemic in 2020 into three distinct strategic approaches. For countries that did not explicitly announce their response strategies, the categorisation was derived from position statements on the goals of national responses by government officials or the intention of public health interventions implemented in the first wave of the pandemic. The strategies were defined as:

- Aggressive containment-countries aimed to eliminate community transmission and achieved elimination status for 28 consecutive days by implementing public health interventions

- Suppression-countries aimed to suppress and minimise community infections by implementing public health interventions

- Mitigation-countries aimed to avoid overwhelming health systems by flattening the epidemic curve or achieving herd immunity in the population. The public health interventions focused on protecting vulnerable and high risk groups while allowing transmission among low risk groups.

Public health interventions were categorised as:

- Population based interventions-such as lockdowns, face masks, social distancing, and personal hygiene

- Case based interventions-include case detection, contact tracing of confirmed cases, isolation, and surveillance of cases

- Border control measures-such as travel restrictions for travellers from high risk countries or mandatory quarantine requirements.

\section{Aggressive containment}

Aggressive containment was the predominant strategy in Asian and Pacific countries, such as China, New Zealand, and Singapore (table 1). With clearly defined targets, these countries achieved zero community cases in the first year of the pandemic. 
As of 16 November 2021, China (3.2) and New Zealand (6.8) are among the countries with the least cumulative deaths per million people; this number has rapidly increased in Singapore (112.2) since the country transitioned towards endemicity in September $2021 .^{13}$

Table 1| Performance of countries that adopted the aggressive containment strategy in the first year of the pandemic

\begin{tabular}{|c|c|c|c|c|c|c|}
\hline \multirow[t]{2}{*}{ Country } & \multirow{2}{*}{$\begin{array}{l}\text { Deaths per million by } \\
\text { the end of } 2020^{10}\end{array}$} & \multicolumn{4}{|c|}{ Quarterly GDP change in 2020 versus the same period in $2019(\%)^{1112}$} & \multirow[t]{2}{*}{ Results } \\
\hline & & Q1 & Q2 & Q3 & Q4 & \\
\hline China & 3.2 & -6.8 & 3.2 & 4.9 & 6.5 & $\begin{array}{l}\text { The lockdown in Wuhan } \\
\text { was lifted after no } \\
\text { community cases for } 14 \\
\text { consecutive days. } \\
\text { Clusters of community } \\
\text { transmission started to } \\
\text { emerge in other parts of } \\
\text { China in April } 2020 \text {. China } \\
\text { upgraded the alert level } \\
\text { and the corresponding } \\
\text { control measures in } \\
\text { communities where } \\
\text { clusters were identified. }\end{array}$ \\
\hline New Zealand & 5.1 & 0.1 & -10.2 & 1.4 & 0.1 & $\begin{array}{l}\text { New Zealand's daily case } \\
\text { number reached zero } \\
\text { before the government } \\
\text { downgraded the alert } \\
\text { level on } 27 \text { April } 2020 \text {. }\end{array}$ \\
\hline Singapore & 4.9 & -0.3 & -13.3 & -5.8 & -2.4 & $\begin{array}{l}\text { Singapore made decisions } \\
\text { on lifting the covid-19 } \\
\text { "circuit breaker" based on } \\
\text { predefined criteria, } \\
\text { including daily case } \\
\text { numbers reaching zero or } \\
\text { a single digit over a } \\
\text { sustained period. } \\
\text { Considering the high } \\
\text { transmissibility of the new } \\
\text { variant, Singapore has } \\
\text { tightened control } \\
\text { measures since May } \\
\text { 2021, banning mass } \\
\text { gathering events and } \\
\text { prohibiting dining in } \\
\text { restaurants. }\end{array}$ \\
\hline
\end{tabular}

\section{Case based interventions}

Strict measures to identify, trace, and isolate covid-19 cases were commonly implemented in these countries. ${ }^{14}$ Surveillance needs to be sensitive and geographically comprehensive to provide a timely and accurate understanding of disease burden. ${ }^{15}$ In addition to passive testing of symptomatic people, these countries also took an active surveillance approach. In China, multiple rounds of population testing were conducted for all residents in cities where outbreaks occurred. Surveillance testing of high risk groups was also implemented in China, New Zealand, and Singapore, aiming to identify community cases at an early stage.

These countries made great efforts to increase capacities for testing, contact tracing, and isolation. China and Singapore ramped up test kit production to meet accelerating demand. All three countries scaled up laboratory capacity, including building new laboratories, decentralising testing services, and training laboratory personnel. Contact tracing was implemented stringently: all three countries required contact tracing for all cases using a forward tracing approach that looks for case contacts from symptom onset. Close contacts were isolated either in government designated facilities or at home. In Singapore, spot checks were carried out to ensure people adhered to quarantine orders. Innovative technologies were widely used to facilitate contact tracing. ${ }^{16}$ An app that allows people to scan a QR code at businesses they visit was used in all three countries to document their location and visit time. ${ }^{17}$

\section{Population based interventions}

Countries that aimed for containment implemented intensive population level interventions to curb community transmission early in the pandemic. China, New Zealand, and Singapore implemented lockdown ${ }^{18}$ either in high burden regions or nationally. Initial lockdowns were more stringent and longer than in countries pursuing other strategies-venues and events involving gatherings were banned, and mobility restrictions were imposed, such as limited access to public spaces except for essential business.

China implemented mandatory mask wearing soon after the outbreak in Wuhan in January 2020. Singapore and New Zealand adopted it in April and June 2020, respectively. To mitigate the effects of population based interventions, all three countries launched socioeconomic support for businesses, households, and the economy, such as subsidised loans for small businesses (New Zealand), poverty subsidies (China), or job support programmes (Singapore). These countries viewed the route to economic recovery as only possible by containing the pandemic. 


\section{Border control measures}

Countries implemented strict travel restrictions to keep their borders closed to most visitors. Testing and mandatory 14 day quarantine were required for travellers entering China, New Zealand, and Singapore. The governments provided surveillance testing for workers at ports of entry; phone based technology was used to monitor the health status of inbound travellers in quarantine.

\section{Community engagement}

All three countries rolled out comprehensive media campaigns across multiple platforms urging the public to adhere to prevention measures. They also proactively engaged communities to plan, deliver, or promote adherence. China used community workers to educate residents about covid-19 prevention measures, provide directions to nearby testing and quarantine facilities, and distribute necessities to residents. Singapore used volunteers to educate older people who lived by themselves about prevention measures.

\section{Factors influencing strategic choices and actions}

A strong commitment to tackling covid-19 from the heads of government prompted immediate action at the beginning of the pandemic. Learning from past experiences with the SARS outbreak in 2003, China and Singapore had strengthened their preparedness for public health emergencies. The Singaporean government was committed to improving pandemic preparedness and constructed a fit-for-purpose infectious diseases centre to be used in times of emergencies. Policy makers were receptive to scientific input from expert groups and committees, enabling these countries to formulate evidence driven national covid-19 responses-for example, an expert committee of infectious disease experts, public health specialists, and clinical infectious disease doctors was formed during the first month of the outbreak in Wuhan, which played a central role in making decisions on response strategies.

\section{Suppression}

Countries that adopted the suppression strategy include Argentina, Uganda, and the United States (table 2). As of 16 November 2021, Argentina (2549.9) and the US (2300.3) were among the countries with the most cumulative deaths per million people; Uganda (68.8) had much lower cumulative deaths per million people than other countries using the suppression strategy. ${ }^{13}$

Table 2 | Performance of countries that adopted the suppression strategy in the first year of the pandemic

\begin{tabular}{|c|c|c|c|c|c|c|}
\hline \multirow[t]{2}{*}{ Country } & \multirow{2}{*}{$\begin{array}{l}\text { Deaths per million by } \\
\text { the end of } 2020^{10}\end{array}$} & \multicolumn{4}{|c|}{ Quarterly GDP change in 2020 versus the same period in $2019(\%)^{11} 19$} & \multirow[t]{2}{*}{ Results } \\
\hline & & Q1 & Q2 & Q3 & Q4 & \\
\hline Argentina & 948.2 & -4.8 & -19.9 & -10.2 & -4.6 & $\begin{array}{l}\text { Intensive control } \\
\text { measures were } \\
\text { implemented between } \\
\text { March and April } 2020 \text { and } \\
\text { eased in May } 2020 \text {. The } \\
\text { government tightened } \\
\text { control measures } \\
\text { (including a new } \\
\text { lockdown) when daily } \\
\text { incidence started to surge } \\
\text { in May 2021. }\end{array}$ \\
\hline Uganda & 5.3 & 1.8 & -6.0 & -2.2 & 1.6 & $\begin{array}{l}\text { Uganda's stringent } \\
\text { measures enabled the } \\
\text { country to maintain a low } \\
\text { number of daily cases } \\
\text { since May } 2020 \text {. In June } \\
2021 \text {, as the second } \\
\text { epidemic wave started, } \\
\text { the country re-introduced } \\
\text { mobility restrictions and } \\
\text { school closure. }\end{array}$ \\
\hline US & 1056.6 & 0.6 & -9.1 & -2.9 & -2.3 & $\begin{array}{l}\text { The epidemic curve } \\
\text { started to flatten in April } \\
2020 \text { after many states } \\
\text { implemented stringent } \\
\text { control measures in } \\
\text { March and April. A second } \\
\text { epidemic wave started in } \\
\text { June } 2020 \text { after } \\
\text { relaxation of public health } \\
\text { interventions in many } \\
\text { states, and a third wave } \\
\text { started in October } 2020 .\end{array}$ \\
\hline
\end{tabular}

\section{Case based interventions}

Guidance on testing eligibility was based on available resources and the epidemiological situation in each country. Argentina and the US prioritised testing for high risk groups in the first half of 2020 and decentralised testing services to private laboratories. Uganda surged testing capacity by modifying existing laboratories to make them appropriate for testing covid-19 and purchased test kits on the international market to ensure adequate stocks. The testing capacity in these countries was stretched by limited testing sites and laboratories and shortage of testing kits and technicians. 
Contact tracing was implemented with different approaches and stringency in each country. Argentina did not implement consistent contact tracing until May 2020 with the Detectar programme. ${ }^{20}$ In the US, contact tracing was the responsibility of states and counties, which used different implementation models, funding, workforce, and policies. ${ }^{21}$ As cases increased, financial shortage and overwhelming workload were the common challenges for implementing contact tracing stringently in the US and Uganda. In the US, reluctance to provide contacts was an additional challenge, leading to less than one contact per case identified on average in some regions. ${ }^{21}$ To support its surveillance system, the US launched syndromic surveillance, which monitors cases that meet the clinical definition of covid-19 without confirmation by testing.

\section{Population based interventions}

These countries implemented intensive population interventions to contain community transmission in the early phase of the pandemic (see supplementary file for specific interventions). In Argentina, a national lockdown started in March 2020, with exemptions for people providing essential services. Many states in the US issued "stay at home" orders in March or April 2020, which remained in place until mid-May. Schools and non-essential businesses were closed. A national lockdown was imposed in Uganda at the end of March 2020. But lockdown in these countries was relaxed before community transmission was eliminated. As evidence on face masks emerged, Argentina, Uganda, and many US states introduced mandatory mask wearing in April and May 2020.

Countries that aimed for suppression saw a trade-off between public health measures and economic growth, emphasising economic recovery during relaxation periods. Despite this, multiple epidemic waves and subsequent tightening of restrictions resulted in all countries providing fiscal stimulus for businesses and employment protection.

\section{Border control measures}

Travel restrictions, such as suspension of flights from high risk countries and temporary border closure, were imposed in all three countries in the early months of the pandemic but were gradually lifted towards the end of 2020. Although proof of negative test results was commonly required for inbound travellers, quarantine requirements varied in stringency across countries. All travellers to Uganda were required to isolate at government facilities for 14 days, whereas home quarantine was allowed in the US and Argentina.

\section{Community engagement}

Countries aiming for suppression developed risk communication strategies that leveraged media platforms to reach the masses while local non-governmental organisations reached out to communities on the ground. Community engagement activities were also common in these countries. In Uganda, for example, community volunteers warned the public about the consequences of violating control measures when fewer deaths and cases led to a rise in complacency among the public.

\section{Factors influencing strategic choices and actions}

Partisan politics in countries such as the US led to mixed messages and lack of commitment from the government to mount a timely and effective response to the pandemic, resulting in high loss of lives. ${ }^{22}$ US political leaders discredited scientific advisers, contributing to delay and lack of coordination in its covid-19 response. ${ }^{23}$ Uganda was relatively better prepared for public health emergencies, having previously dealt with Ebola outbreaks. Argentina and the US were less prepared, partially owing to limited experiences of responding to large scale epidemics or underfunded public health systems.

\section{Mitigation}

Sweden maintained a mitigation strategy from the start of the pandemic; the United Kingdom initially aimed for mitigation but shifted towards suppression as the pandemic escalated (table 3 ). By 16 November 2021, Sweden (1485.6) and the UK (2105.3) were among the countries with the highest cumulative deaths per million people in the world. ${ }^{13}$ 
Table 3 | Performance of countries that adopted the mitigation strategy in the first year of the pandemic

\begin{tabular}{|c|c|c|c|c|c|c|}
\hline \multirow[t]{2}{*}{ Country } & \multirow[t]{2}{*}{$\begin{array}{l}\text { Deaths per million by } \\
\text { the end of } 2020^{10}\end{array}$} & \multicolumn{4}{|c|}{$\begin{array}{l}\text { Quarterly } \\
\text { GDP change in } 2020 \text { versus the same period in } 2019(\%)^{11}\end{array}$} & \multirow[t]{2}{*}{ Results } \\
\hline & & Q1 & Q2 & Q3 & Q4 & \\
\hline Sweden & 858.9 & 0.1 & -8.2 & -1.9 & -1.8 & $\begin{array}{l}\text { The government } \\
\text { introduced more stringent } \\
\text { control measures in } \\
\text { November } 2020 \text {, such as } \\
\text { banning social gatherings. } \\
\text { In December } 2020 \\
\text { hospitals in Stockholm } \\
\text { were under severe } \\
\text { pressure and intensive } \\
\text { care beds almost reached } \\
\text { capacity. }\end{array}$ \\
\hline UK & 1079.4 & -2.2 & -21.4 & -8.1 & -7.1 & $\begin{array}{l}\text { The UK switched to } \\
\text { suppression in April } 2020 \\
\text { and daily incidence began } \\
\text { to decline. The country } \\
\text { maintained a relatively } \\
\text { stable number of daily } \\
\text { cases and deaths before } \\
\text { easing public health } \\
\text { interventions in June } \\
2020 \text {. As cases started to } \\
\text { rise in September 2020, } \\
\text { the government } \\
\text { tightened public health } \\
\text { measures again. }\end{array}$ \\
\hline
\end{tabular}

\section{Case based interventions}

Countries that aimed for mitigation delayed efforts to increase capacity for testing and contact tracing capacity. Sweden introduced testing for travellers returning from high risk countries in February 2020. After the eligibility for testing was expanded to priority groups, insufficient access to testing was reported in many regions. In the UK, people with symptoms suspected of covid-19 were not eligible for testing in the early months of the pandemic. After the government decided to increase testing capacity in May 2020, eligibility expanded.

Contact tracing policies were inconsistent over the course of the pandemic, with delayed efforts to increase capacity. In Sweden, contact tracing was implemented at the start of the pandemic but was abandoned after a few weeks due to stretched human resources. In the UK, full contact tracing was abandoned in line with the move from contain to delay phase in March 2020. After receiving additional funding from the government, a new contract tracing system was launched in May 2020. However, it did not function effectively as expected, as tracers failed to get in touch with one in eight confirmed cases. ${ }^{21}$ Both countries took measures to strengthen surveillance of covid-19 cases, such as conducting large-scale surveillance studies or deploying sentinel surveillance.

\section{Population level interventions}

Countries that adopted the mitigation strategy had less stringent population level interventions (see supplementary file for specific interventions) but gradually tightened them as the pandemic evolved. Instead of imposing lockdowns, Sweden issued recommendations for maintaining physical distance in schools, workplaces, and public places. Social and mass gatherings were banned in both countries. As daily cases increased, the UK moved towards a suppression strategy, marked by the announcement of lockdown in March 2020. The lockdown relaxed in June 2020 as the epidemic curve flattened. Mask wearing was not recommended for the public in these countries in the first six months, given the lack of evidence on its effectiveness. There was no national recommendation for mask wearing for the public in Sweden. In the UK, mask wearing was not mandatory until June 2020. Both countries offered socioeconomic support, such as the furlough scheme that paid wages of employees who lost their jobs owing to the pandemic (UK) and small businesses loans (Sweden).

\section{Border control measures}

Sweden did not require testing for symptom-free travellers before entering, and arriving travellers were not obliged to quarantine. The UK initially had no specific testing requirements for travellers. The government advised against non-essential travelling to high risk countries but did not impose travel bans or border closure. In June 2020, however, the UK tightened measures at the borders, including 14 day self-isolation for arriving travellers.

\section{Community engagement}

Risk communication was largely conducted on media platforms with limited community engagement. Press conferences by the Swedish Public Health Agency were held regularly and broadcast on television and the internet; digital platforms and hotlines were established to help people with migrant backgrounds access covid-19 information. Similarly, in the UK, updates on the epidemic situation or control measures were disseminated through regular press briefings.

\section{Factors influencing strategic choices and actions}

There was broad consensus on adopting a more relaxed response to covid-19 among politicians in Sweden, in line with its constitution, but policy makers in the UK took a "wait and see approach" through public statements, reassuring the public despite increasing domestic cases. When public health interventions were enacted, the population had already heard mixed messages about the need for a response. 


\section{Benefits, challenges, and trade-offs}

The three strategies have their own benefits, challenges, and trade-offs (table 4). Although factors such as culture, demographics, and geography have contributed to how the pandemic and responses unfolded, countries that opted for aggressive containment had lower deaths per million than those that took other approaches.

Table 4 | Summary of benefits, challenges, and trade-offs of each strategy

\begin{tabular}{|c|c|c|c|}
\hline Strategy & Benefits & Challenges & Trade-offs \\
\hline Aggressive containment & $\begin{array}{l}\text { Lowest deaths per million. } \\
\text { Quicker economic recovery. }\end{array}$ & $\begin{array}{l}\text { Requires resources and infrastructure to build } \\
\text { increased capacities in a short time. }\end{array}$ & $\begin{array}{l}\text { Stringent mobility restrictions may increase } \\
\text { unemployment and reduce access to social and } \\
\text { health services. } \\
\text { Restriction of civil liberties and raises concerns } \\
\text { about privacy infringement when aggressive } \\
\text { contact tracing measures are taken. }\end{array}$ \\
\hline Suppression & $\begin{array}{l}\text { Reduces covid-19 burden in the short term, } \\
\text { thus avoiding overwhelming the health system. }\end{array}$ & $\begin{array}{l}\text { Easing control measures before eliminating } \\
\text { community transmission can lead to resurgence } \\
\text { and excessive deaths. } \\
\text { Recurrent public health interventions can cause } \\
\text { fatigue, undermining the effectiveness of the } \\
\text { interventions. }\end{array}$ & $\begin{array}{l}\text { Stringent mobility restrictions may increase } \\
\text { unemployment and reduce access to social and } \\
\text { health services. }\end{array}$ \\
\hline Mitigation & Preserves freedom of movement. & $\begin{array}{l}\text { Older people are not completely protected from } \\
\text { infection, so the health system can be } \\
\text { overwhelmed, resulting in excessive deaths. }\end{array}$ & $\begin{array}{l}\text { High death rates comparable to countries } \\
\text { following the suppression strategy. But contrary } \\
\text { to common belief, they also suffered from } \\
\text { economic contraction and a slow recovery in } \\
\text { the first year. }\end{array}$ \\
\hline
\end{tabular}

A concern of aggressive containment is the potential economic cost attributable to the maintenance of stringent measures. We found, however, that countries using all strategies needed to introduce similar socioeconomic support measures. This supports emerging research that containment might actually protect the economy by reducing uncertainty and allowing for a faster recovery, resulting in less spending on socioeconomic measures and better economic returns owing to lower morbidities and mortalities. ${ }^{24-26}$ Most countries employing aggressive containment achieved economic growth in the third and fourth quarters of 2020 (table 1), whereas countries following other strategies showed a sustained decline in gross domestic product (GDP) (table 2, table 3). Overall, countries that implemented aggressive containment saw less fluctuation in weekly GDP and quicker recovery in the first year of the pandemic, which supports the strategy's potential to protect lives and livelihoods better than suppression or mitigation approaches. ${ }^{27}$ Successful containment is underpinned by a country's ability to rapidly mobilise resources and expand health system capacity, so lower income countries might face challenges.

Even if countries manage to implement aggressive containment measures, some trade-offs remain. Despite favourable health and economic outcomes, aggressive containment has been criticised for restricting civil liberties and raises concerns about privacy infringement when aggressive contact tracing measures are taken. ${ }^{28}$ But civil liberties can be restored quickly in countries that achieved containment, whereas research shows that liberties were severely impacted in countries following other strategies where mobility restrictions were often implemented more strictly. ${ }^{29}$ Aggressive containment also disrupts employment and reduces access to social and health services, bearing social and economic costs that need to be balanced with the cost of lives lost. ${ }^{30}$

Suppression can reduce covid-19 burden in the short term, but easing control measures before eliminating community transmission can lead to a resurgence of cases, resulting in epidemic waves and excessive deaths. Recurrent public health interventions can cause fatigue in the population, leading to higher non-compliance in subsequent pandemic waves. ${ }^{31}$ Countries employing the suppression strategy, such as Argentina and the US, had some of the highest mortalities in the world and also experienced steep economic downturns and slow recovery in 2020 (table 2). Having much lower deaths per million, Uganda seems to be more resilient to the health effects of the pandemic, possibly as lower income countries have younger populations that are less affected by the disease than higher income countries. ${ }^{7}$ Owing to a large informal labour sector, however, lower income countries are more vulnerable to the socioeconomic repercussions of stringent public health interventions. The governments often lack fiscal space and an accountable administrative system to tackle these unintended consequences. 3233 Thus, the benefits of adopting the suppression strategy to reduce mortality might be less substantial when compared to the corresponding economic loss. 34

Countries that opted for mitigation preserved the freedom of movement of their citizens, but this seems risky, particularly in higher income countries with older populations, where health systems might get stretched or even overwhelmed, resulting in excessive deaths. ${ }^{27}$ Both Sweden and the UK had death rates comparable to countries adopting the suppression strategy (table 3). These countries also experienced a slow economic recovery after a steep economic decline in the second quarter of 2020, as seen in Sweden's and the UK's economic contraction in the third and fourth quarter of 2020 (table 3).

\section{Steps to achieving successful containment}

Our analysis shows that containing community transmission is the optimal strategy to save lives and protect the economy and is achievable in the absence of vaccines and effective drugs. We identified the interventions, actions, and determinants that contribute to successful containment (fig 1). Determining when public health interventions are implemented and lifted is central to success. Countries must take immediate action in response to a disease outbreak. Premature lifting of public health interventions leads to epidemic waves, causing even more deaths and damage to the economy. ${ }^{35}{ }^{36}$ Countries that aimed for containment clearly defined the goal of eliminating community transmission and made exit decisions based on explicit indicators. 


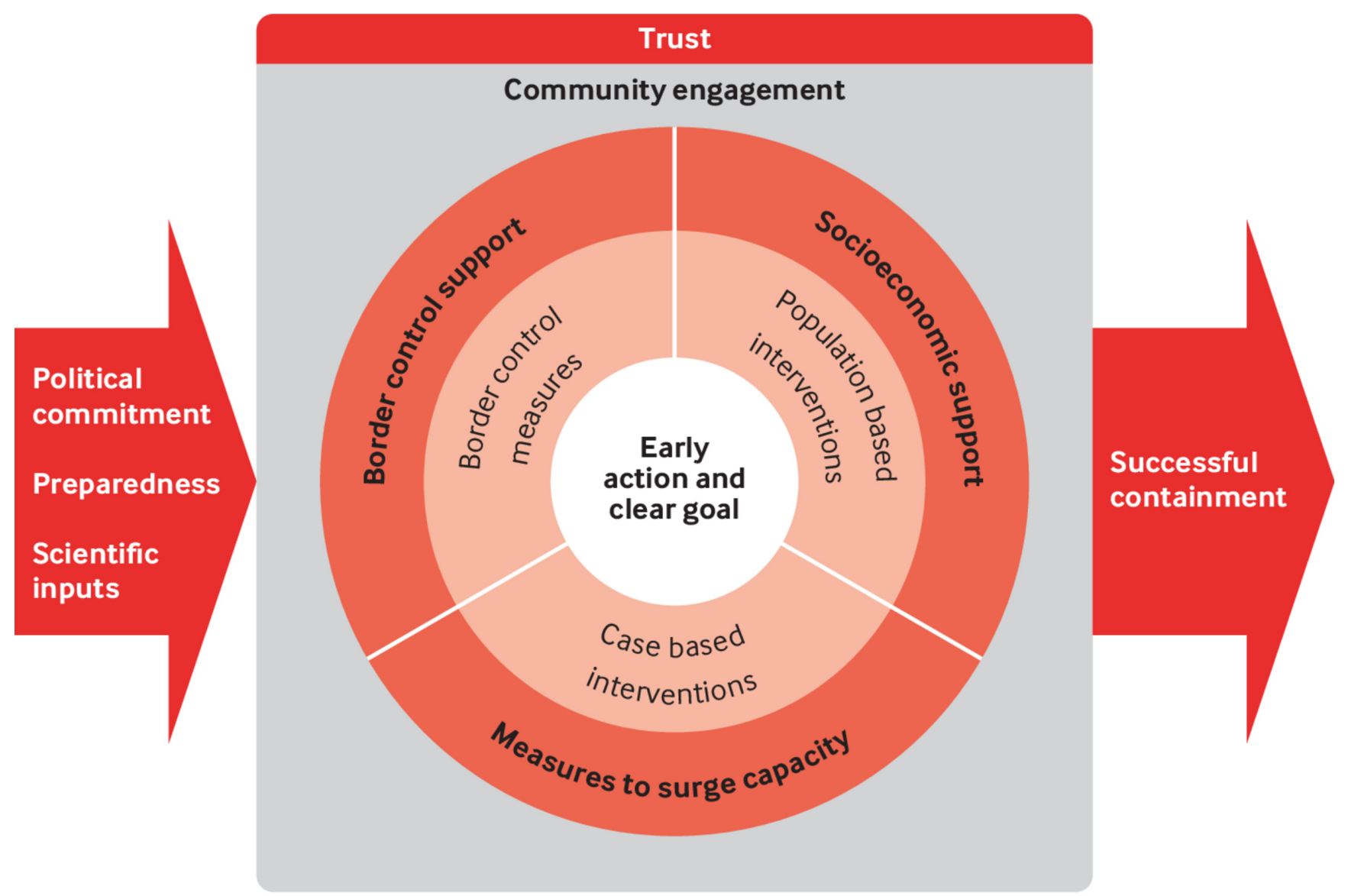

Fig 1 | An illustration of steps to achieving successful containment by using public health interventions built on trust and community engagement coupled with strong political will, health system preparedness, and receptiveness to scientific inputs

Countries need to implement all three categories of public health interventions comprehensively, with support measures for increasing capacity and mitigating the socioeconomic repercussions. Countries successful in containment implemented intensive population based interventions, such as multiple national or subnational lockdowns to curb community transmission. They delivered a range of socioeconomic support to provide safety nets for affected and vulnerable populations and quickly introduced measures to identify, trace, and isolate cases in communities and at borders. To ensure these measures could be delivered comprehensively and stringently, these countries made efforts to increase public health capacity and strengthen border control as the pandemic escalated. Support packages also improved the effectiveness of case based interventions like isolation. In the US, for example, provision of food deliveries and additional financial support to those in isolation was found to enhance compliance. ${ }^{37}$ Countries that opted for mitigation or suppression focused on population based interventions, but they often sidelined or were hesitant towards case based and border control measures-most of these countries delayed efforts to increase public health capacity, suspended contact tracing, and maintained relaxed border control.

Successful containment is underpinned by the public's trust in policy makers and the government. Effective community engagement, achieved through strong community leadership and coordination, was fundamental to Ebola responses, leading to increased trust in health authorities. ${ }^{38-40}$ During the covid-19 pandemic, New Zealanders trusted and supported the interventions implemented by their government, resulting in high compliance initially, which declined over time owing to fatigue and complacency..$^{41}$ To maintain adherence, two way community engagement through a whole-of-society approach ensures that all stakeholders understand the rationale for tightening or sustaining measures. Notably, trust and community engagement are integral when technology is involved in contact tracing. The US and UK faced challenges in their populations' trust in the government's data management and privacy regulations, which affected the uptake of contact tracing applications and thus reduced their effectiveness. ${ }^{42} 43$ By engaging the community and implementing privacy safeguards, contact tracing applications offer faster tracing and ringfencing, and is therefore postulated to contribute to successful containment. 44

Three factors influence strategic choices and the success of containment. First, strong political will and commitment to tackling covid-19 prompted immediate actions, multi-sectoral collaboration, and rapid resource mobilisation through a whole-of-government, whole-of-society governance approach in successful countries. ${ }^{45}$ Second, a country's response capacity depends on its public health preparedness. ${ }^{46}$ The effectiveness of responses depends on the country having a well maintained public health system to perform its core functions and manage logistics in emergencies. ${ }^{47}$ Countries have been asked to strengthen their preparedness for public health emergencies by implementing the Global Health Security Agenda and International Health Regulations. ${ }^{48}$ But most countries lack robust preparedness plans and core public health capacities, as 
their public health systems are vastly underfunded and neglected. $495^{\circ}$ Successful countries drew lessons from past outbreaks to inform decisions on control measures and adapt their public health systems quickly. ${ }^{51}$ The lack thereof, coupled with the absence of aggressive containment measures, has been documented to overwhelm health systems, increasing the mortality risks for patients with covid-19..$^{\circ}$ Finally, successful containment is more likely to be achieved with scientific input. Up to date research evidence is the foundation for making optimal decisions on control measures to be implemented or relaxed, but the supply of scientific evidence does not guarantee its uptake. Hence it is critical to establish mechanisms to ensure that evidence is incorporated in policy making. In countries adopting the aggressive containment strategy, independent expert committees, formed after the declaration of the pandemic, commonly spearheaded the formulation of response strategies and took on key advisory roles in high level policy decision making.

\section{Going forward}

As the world proceeds into covid-19 endemicity, aggressive containment might not be the best way forward. Some, but not all, countries that permitted controlled spread of the virus (thus generating higher natural immunity levels) and had robust vaccination campaigns have been seen to relax public health interventions and are reopening sooner than countries that used aggressive containment and have more naive populations that rely predominantly on the rapid expansion of vaccination coverage. ${ }^{5253}$ Countries that are reopening faster have paid the price in terms of a higher death toll in the earlier stages.

The containment strategy was arguably intended to provide time to develop covid-19 treatments and vaccines, to strengthen health systems, and for informed decision making but not to be a long term response. ${ }^{3654}$ As we cross the pandemic's two year mark, a more sustainable approach that amalgamates acceptable levels of community transmission and high vaccination rates may be the best way for countries that have used aggressive containment to reach a new equilibrium. 5556

\section{Implication of our analysis}

Containing community transmission is the optimal strategy for new emerging infectious hazards and achievable in the absence of vaccines. Our findings further bolster recent research in favour of more stringent responses and extends those findings by including a diverse geographic, sociocultural, and economic sample of countries to analyse response strategies. ${ }^{27} 3036$ The lessons drawn from eight countries are useful to guide the development of a comprehensive response to covid-19 and future pandemics. Although the development of vaccines has raised the hope of returning to normal life, relying solely on vaccines to control the pandemic is uncertain given the inequitable global vaccination rollout. Implementing the aggressive containment strategy-which uses public health interventions built on trust and community engagement coupled with strong political will, health system preparedness, and receptiveness to scientific inputs-will reduce the impact on lives and livelihoods, particularly at the earlier stages of the pandemic. As more countries, including those successful in containment, transition to covid-19 endemicity, continuing investments and efforts are needed to reduce inequalities, enhance health system capacities, and strengthen public health preparedness in the event of potential emergent strains and waning vaccine immunities.

\section{Key messages}

- Aggressive containment of community transmission is the optimal strategy in emerging pandemics to save lives and protect the economy and achievable in the absence of vaccines and treatments

- Successful containment requires countries to take immediate action in response to emerging outbreaks and clearly define the targets for relaxing interventions

- A comprehensive package of public health interventions needs to be implemented stringently with support measures for mitigating the adverse effects and increasing capacity

- Success is underpinned by trust and community engagement and facilitated by strong political commitment, well prepared public health systems, and scientific input into policy making

- Aggressive containment might not be sustainable in the long term. A more sustainable approach which amalgamates acceptable levels of community transmission and high vaccination rates may be the best way forward.

Provenance and peer review: Commissioned; externally peer reviewed.

Contributors and sources: SW and HL-Q conceived and planned the manuscript. SW, RN, and HL-Q drafted the manuscript with inputs from all authors. All authors contributed to revising the manuscript and approved the final version. This analysis was part of the work commissioned by the Independent Panel for Pandemic Preparedness and Response, which reviewed the national responses of 28 countries. Data used for the analysis were collected through three complementary methods: literature review of peer reviewed papers, policy documents, public reports, and articles that examined national and subnational policy responses; semi-structured interviews with country experts and submissions written by the national governments of selected countries about their own account of the measures implemented to contain covid-19; and validation of country specific data by experts through written consultation and round table discussion.

Data for this review were collected under the auspices of the Independent Panel for Pandemic Preparedness and Response. The analysis of this paper is separate from the Independent Panel's Final Report and has been facilitated by the Independent Panel Secretariat. The Secretariat of the Independent Panel for Pandemic Preparedness and Response is independent and impartial. The views expressed in this work are solely that of the authors' and do not represent the views of the Independent Panel for Pandemic Preparedness and Response.

This collection of articles was proposed by The Independent Panel for Pandemic Preparedness and Response, open access fees were funded by WHO and Singapore's National Medical Research Council (NMRC/CG/CO26/2017_NUHS). The BM/commissioned, peer reviewed, edited, and made the decision to publish these articles. Kamran Abbasi was the lead editor for The BMJ.

Patient involvement: No patients were involved in this analysis.

Conflicts of Interest: We have read and understood BMJ policy on declaration of interests and have the following interests to declare: All authors declare no conflict of interest. The Secretariat of the Independent Panel for Pandemic Preparedness and Response is independent.

van Zandvoort K, Jarvis Cl, Pearson CAB, etalCMMID COVID-19 working group. Response strategies for COVID-19 epidemics in African settings: a mathematical modelling study. BMCMed 2020;18:324. doi: 10.1186/s12916-020-01789-2 pmid: 33050951

2 Ferguson N, Laydon D, Nedjati Gilani G, et al. Report 9: Impact of non-pharmaceutical interventions (NPIs) to reduce covid-19 mortality and healthcare demand. 2020. https://www.imperial.ac.uk/mrcglobal-infectious-disease-analysis/covid-19/report-9-impact-of-npis-on-covid-19/

3 Chowdhury R, Heng K, Shawon MSR, etalGlobal Dynamic Interventions Strategies for COVID-19 Collaborative Group. Dynamic interventions to control covid-19 pandemic: a multivariate prediction modelling study comparing 16 worldwide countries. Eur J Epidemiol 2020;35:389-99. doi: 10.1007/s10654-020-00649-w pmid: 32430840

4 Baker MG, Wilson N, Blakely T. Elimination could be the optimal response strategy for covid-19 and other emerging pandemic diseases. BMJ 2020;371:m4907.

doi: 10.1136/bmj.m4907 pmid: 33561814

James A, Hendy SC, Plank MJ, etal. Suppression and mitigation strategies for control of covid-19 in New Zealand.medRxiv 2020doi: 10.1101/2020.03.26.20044677

6 Lee A, Thornley S, Morris AJ, Sundborn G. Should countries aim for elimination in the covid-19 pandemic?BM/2020;370:m3410. doi: 10.1136/bmj.m3410 pmid: 32909958

Walker PGT, Whittaker C, Watson OJ, etal. The impact of covid-19 and strategies for mitigation and suppression in low- and middle-income countries. Science 2020;369:413-22. doi: 10.1126/science.abc0035 pmid: 32532802

8 Kayı İ, Sakarya S. Policy analysis of suppression and mitigation strategies in the management of an outbreak through the example of covid-19 pandemic. Infect Dis Clin Microbiol 2020;2:30-41doi: 10.36519/idcm.2020.0009 
$9 \mathrm{Ng} \mathrm{T}-\mathrm{C}$, Cheng $\mathrm{H}-\mathrm{Y}$, Chang $\mathrm{H}-\mathrm{H}$, etal. Comparison of estimated effectiveness of case-based and population-based interventions on covid-19 containment in Taiwan. JAMA Intern Med 2021;181:913-21. doi: 10.1001/jamainternmed.2021.1644 pmid: 33821922

10 Our World in Data. Total confirmed covid-19 deaths per million. 2021. https://ourworldindata.org/grapher/covid-deaths-per-million-vs-days-since-exemplar?time=2020-01-22.2020-1231\&country=CHN SGP NZL ARG UGA USA $\sim$ SWE $\sim$ GBR

11 OECD. Quarterly GDP. 2021. https://data.oecd.org/gdp/quarterly-gdp.htm

12 Ministry of Trade and Industry Singapore. MTI Upgrades 2021 GDP Growth Forecast to "6.0 to 7.0 Per Cent". 2021. https://www.singstat.gov.sg/-/media/files/news/gdp2q2021.pdf

13 Our World in Data. Cumulative confirmed covid-19 cases per million people. https://ourworldindata.org/explorers/coronavirus-data-explorer?tab=map\&zoomToSelection=true\&country=GBR USA $\sim$ ESP $\sim$ ITA BRA IND KOR\&region=World\&pickerMetric=location\&picker Sort=asc\&hideControls=true\&Interval=Cumulative\&Align+outbreaks=false\&Relative+to+Population=true\&Metric=Confirmed + cases2021

14 Haldane V, De Foo C, Abdalla SM, etal. Health systems resilience in managing the COVID-19 pandemic: lessons from 28 countries. Nat Med 2021;27:964-80. doi: 10.1038/s41591-021-01381-y pmid: 34002090

15 World Health Organization. Public health surveillance for COVID-19: interim guidance, 16 December 2020. 2020. https://apps.who.int/iris/handle/10665/337897.

16 Government of Singapore. Everything you need to know about quarantine orders. Government of Singapore, 2020

17 Ministry of Health New Zealand. NZ covid tracer app. https://www.health.govt.nz/our-work/diseases-and-conditions/COVID-19-novel-coronavirus/COVID-19-resources-and-tools/nz-covidtracer-app

18 World Health Organization. Coronavirus disease (covid-19): herd immunity, lockdowns and covid-19. WHO, 2020

19 Uganda Bureau of Statistics. Quarterly GDP https://www.ubos.org/?pagename=explore-publications\&p_id=1272021

20 Government of Argentina. Se suman nuevas acciones para la detección de casos de covid-19. 2020. https://www.argentina.gob.ar/noticias/se-suman-nuevas-acciones-para-la-deteccion-decasos-de-covid-19

21 Lewis D. Why many countries failed at covid contact-tracing - but some got it right. Nature 2020;588:384-7. doi: 10.1038/d41586-020-03518-4 pmid: 33318682

22 Chen H-F, Karim SA. Relationship between political partisanship and COVID-19 deaths: future implications for public health. J Public Health (Oxf) 2021;fdab136. doi: 10.1093/pubmed/fdab136 pmid: 33912968

23 Tollefson J. How Trump damaged science - and why it could take decades to recover. Nature 2020;586:190-4. doi: 10.1038/d41586-020-02800-9 pmid: 33020603

24 Kochańczyk M, Lipniacki T. Pareto-based evaluation of national responses to COVID-19 pandemic shows that saving lives and protecting economy are non-trade-off objectives.medRxiv 2020

25 König M, Winkler A. Covid-19: lockdowns, fatality rates and GDP growth. Inter Econ2021;56:32-9. doi: 10.1007/s10272-021-0948-y pmid: 33518787

26 Alvelda P, Ferguson T, Mallery J. To save the economy, save people first. Institute for New Economic Thinking. 2020. https://www.ineteconomics.org/perspectives/blog/to-save-the-economy-save-people-first

27 Oliu-Barton M, Pradelski BSR, Aghion P, etal. SARS-CoV-2 elimination, not mitigation, creates best outcomes for health, the economy, and civil liberties. Lancet 2021;397:2234-6. doi: 10.1016/S0140-6736(21)00978-8 pmid: 33932328

28 Illmer A. Singapore reveals Covid privacy data available to police. BBC. 2021. https://www.bbc.com/news/world-asia-55541001

29 Philippe C, Marques N. The Zero Covid strategy protects people, economies and freedoms more effectively. Institut Économique Molinari. 2021. https:/www.institutmolinari.org/2021/09/21/thezero-covid-strategy-continues-to-protect-people-economies-and-freedoms-more-effectively/

30 Meyerowitz-Katz G, Bhatt S, Ratmann O, etal. Is the cure really worse than the disease? The health impacts of lockdowns during COVID-19. BMJ Glob Health 2021;6:e006653. doi: 10.1136/bmigh-2021-006653 pmid: 34281914

31 Norheim OF, Abi-Rached JM, Bright LK, etal. Difficult trade-offs in response to COVID-19: the case for open and inclusive decision making. Nat Med 2021;27:10-3. doi: 10.1038/s41591-020-01204-6 pmid: 33340033

32 Loayza N, Pennings SM. Macroeconomic policy in the time of COVID-19: A primer for developing countries World Bank Research and Policy Briefs, 2020: 147291doi: 10.1596/33540

33 Kaufmann D, Kraay A, Mastruzzi M. The worldwide governance indicators: methodology and analytical issues. Hague J Rule Law 2011;3:220-46doi: 10.1017/S1876404511200046

34 Alon TM, Kim M, Lagakos D, etal. How should policy responses to the covid-19 pandemic differ in the developing world? National Bureau of Economic Research, 2020doi: 10.3386/w27273

35 Goudsmit J. The paramount importance of serological surveys of SARS-CoV-2 infection and immunity. Eur J Epidemiol 2020;35:331-3. doi: 10.1007/s10654-020-00635-2 pmid: 32318914

36 Han E, Tan MMJ, Turk E, etal. Lessons learnt from easing covid-19 restrictions: an analysis of countries and regions in Asia Pacific and Europe. Lancet 2020;396:1525-34 doi: 10.1016/S0140-6736(20)32007-9 pmid: 32979936

37 Kerkhoff AD, Sachdev D, Mizany S, etal. Evaluation of a novel community-based covid-19 "test-to-care" model for low-income populations. PLoS One 2020;15:e0239400. doi: 10.1371/journal.pone.0239400 pmid: 33035216
38 Barker KM, Ling EJ, Fallah M, etal. Community engagement for health system resilience: evidence from Liberia's Ebola epidemic. Health Policy Plan 2020;35:416-23. doi: 10.1093/heapol/czz174 pmid: 32040166

39 Gillespie AM, Obregon R, El Asawi R, etal. Social mobilization and community engagement central to the Ebola response in West Africa: lessons for future public health emergencies. Glob Health Sci Pract 2016;4:626-46. doi: 10.9745/GHSP-D-16-00226 pmid: 28031301

40 Carter SE, O’Reilly M, Frith-Powell J, Umar Kargbo A, Byrne D, Niederberger E. Treatment seeking and Ebola community care centers in Sierra Leone: a qualitative study. J Health Commun 2017;22(sup1):66-71. doi: 10.1080/10810730.2016.1216204 pmid: 28854139

41 Gray L, Rose SB, Stanley J, etal. Factors influencing individual ability to follow physical distancing recommendations in Aotearoa New Zealand during the COVID-19 pandemic: a population survey. J R Soc N Z2021;51:S107-26doi: 10.1080/03036758.2021.1879179

42 Bradford L, Aboy M, Liddell K. COVID-19 contact tracing apps: a stress test for privacy, the GDPR, and data protection regimes. J Law Biosciences 2020;7:Isaa034.

43 Lapolla P, Lee R. Privacy versus safety in contact-tracing apps for coronavirus disease 2019. Digit Health 2020;6:2055207620941673. doi: 10.1177/2055207620941673 pmid: 32728475

44 Goggin G. COVID-19 apps in Singapore and Australia: reimagining healthy nations with digital technology. Media Int Aust 2020;177:61-75doi: 10.1177/1329878X20949770

45 Duong DM, Le VT, Ha BTT. Controlling the COVID-19 Pandemic in Vietnam: Lessons From a Limited Resource Country. Asia Pac J Public Health 2020;32:161-2. doi: 10.1177/1010539520927290 pmid: 32429676

46 World Health Organization. Thematic paper on the status of country preparedness capacities. 2019. https://www.gpmb.org/annual-reports/overview/item/thematic-paper-on-the-status-ofcountry-preparedness-capacities

47 Kandel N, Chungong S, Omaar A, Xing J. Health security capacities in the context of covid-19 outbreak: an analysis of International Health Regulations annual report data from 182 countries. Lancet 2020;395:1047-53. doi: 10.1016/S0140-6736(20)30553-5 pmid: 32199075

48 World Health Organization. Global Preparedness Monitoring Board. Annual report on global preparedness for health emergencies. 2019. https://www.gpmb.org/annual-reports/annual-report 2019

49 Sirleaf E), Clark H. Report of the Independent Panel for Pandemic Preparedness and Response: making covid-19 the last pandemic. Lancet 2021;398:101-3. doi: 10.1016/S0140-6736(21)01095-3 pmid: 33991477

50 Wilde $\mathrm{H}$, Mellan T, Hawryluk I, etal. The association between mechanical ventilator availability and mortality risk in intensive care patients with COVID-19: A national retrospective cohort study.medRxiv2021. https://www.medrxiv.org/content/10.1101/2021.01.11.21249461v1

51 Chua AQ, Al Knawy B, Grant B, etal. How the lessons of previous epidemics helped successful countries fight covid-19. BMJ2021;372:n486. doi: 10.1136/bmj.n486 pmid: 33707174

52 Makary M. The power of natural immunity. Wall Street Journal. 2021. https://www.wsj.com/articles/the-power-of-natural-immunity-11623171303

53 Ho G. Zero-covid strategy no longer feasible due to highly infectious Delta variant: PM Lee. Straits Times2021. https://www.straitstimes.com/singapore/politics/spore-must-press-on-with-strategy of-living-with-covid-19-and-not-be-paralysed-by

54 De Foo C, Grépin KA, Cook AR, etal. Navigating from SARS-CoV-2 elimination to endemicity in Australia, Hong Kong, New Zealand, and Singapore. Lancet 2021;398:1547-51. doi: 10.1016/S0140-6736(21)02186-3 pmid: 34619099

55 Lokuge K, Banks E, Davis S, etal. Exit strategies: optimising feasible surveillance for detection, elimination, and ongoing prevention of covid-19 community transmission. BMCMed2021;19:50 doi: 10.1186/s12916-021-01934-5 pmid: 33596902

56 Phillips N. The coronavirus is here to stay-here's what that means. Nature 2021;590:382-4. doi: 10.1038/d41586-021-00396-2 pmid: 33594289

This is an Open Access article distributed under the terms of the Creative Commons Attribution IGO License (https://creativecommons.org/licenses/by-nc/3.0/igo/), which permits use, distribution, and reproduction for non-commercial purposes in any medium, provided the original work is properly cited. 